University for Business and Technology in Kosovo

UBT Knowledge Center

UBT International Conference

2018 UBT International Conference

Oct 27th, 1:30 PM - 3:00 PM

\title{
Analytical Evaluation of Paper Degradation
}

Drita Abazi

Mother Teresa University - Universiteti Nënë Tereza, drita.abazi@unt.edu.mk

Teresa Ferreira

University of Évora

Cristina Barrocas Dias

University of Évora

Ana Manhita

University of Évora

Margarida Nunes

University of Évora

See next page for additional authors

Follow this and additional works at: https://knowledgecenter.ubt-uni.net/conference

Part of the Food Science Commons

\section{Recommended Citation}

Abazi, Drita; Ferreira, Teresa; Dias, Cristina Barrocas; Manhita, Ana; Nunes, Margarida; and Aliu, Suzana, "Analytical Evaluation of Paper Degradation" (2018). UBT International Conference. 160.

https://knowledgecenter.ubt-uni.net/conference/2018/all-events/160

This Event is brought to you for free and open access by the Publication and Journals at UBT Knowledge Center. It has been accepted for inclusion in UBT International Conference by an authorized administrator of UBT Knowledge Center. For more information, please contact knowledge.center@ubt-uni.net. 


\section{Presenter Information}

Drita Abazi, Teresa Ferreira, Cristina Barrocas Dias, Ana Manhita, Margarida Nunes, and Suzana Aliu 


\title{
Analytical Evaluation of Paper Degradation
}

\author{
Drita Abazi $^{1}$, Teresa Ferreira ${ }^{1}$, Cristina Barrocas Dias ${ }^{1}$, Ana Manhita, Margarida \\ Nunes ${ }^{1}$, Suzana Aliu ${ }^{2}$ \\ UNT - Shkup \\ ${ }^{1}$ Hercules Laboratory, University of Évora, Largo Marques do Marialva 8, 7000-809 \\ Évora, Portugal \\ ${ }^{2}$ UBT Higher Education Institution, Lagjja Kalabria p.n., Prishtinë, Kosovë \\ drita.abazi@unt.edu.mk_suzana.aliu@ubt-uni.net
}

\begin{abstract}
In this paper the object of study was to determine the chemical nature of foxing stains in paper. Purpose of the study: Was to deepen the knowledge on the paper with special emphasis on foxing stains, their chemical nature and morphological aspects of foxing stains. Methods used: Are photography under different illuminations and optical microscopy. The presence of fibers disruption was observed with (SEM-EDS), it was used also (ATR-FTIR). Micro X-ray diffraction was used to evaluate the crystalline fillers in the sample. Mass Spectrometry was used for chemical analysis to identify the organic components. Conclusion: Unfoxed and foxed areas of paper samples showed no differences from a morphological point of view. The sample' surface was structurally organized, paper fibers seem to be in good condition, without any visible disturbance. The combination of several non-destructive techniques allowed the characterization of paper composition and the evaluation of morphological aspects.
\end{abstract}

Key words: Stains, Cellulose fibers, Chemical analysis, Organic compounds.

\section{Introduction}

Paper is a complex matrix, being the main components cellulose, hemicellulose and lignin, eventually in significant amounts. It also contains others components such as non-fibrous materials, like fillers, coatings and sizing materials.

People had always tried to find out something easier to write on than papyrus or parchment, that at the same time, should be easier and cheaper to make. People used various ways to express through writing in particular palm leaves, whale bone, seal teeth, shells, turtle shell, and more subsequently, silk and bamboo. It was also common to use stone, clay and even tree bark.

\section{Methods and Materials}

For this study were used paper samples which were collected from stationary shops in Lisbon, from different manufactures. 

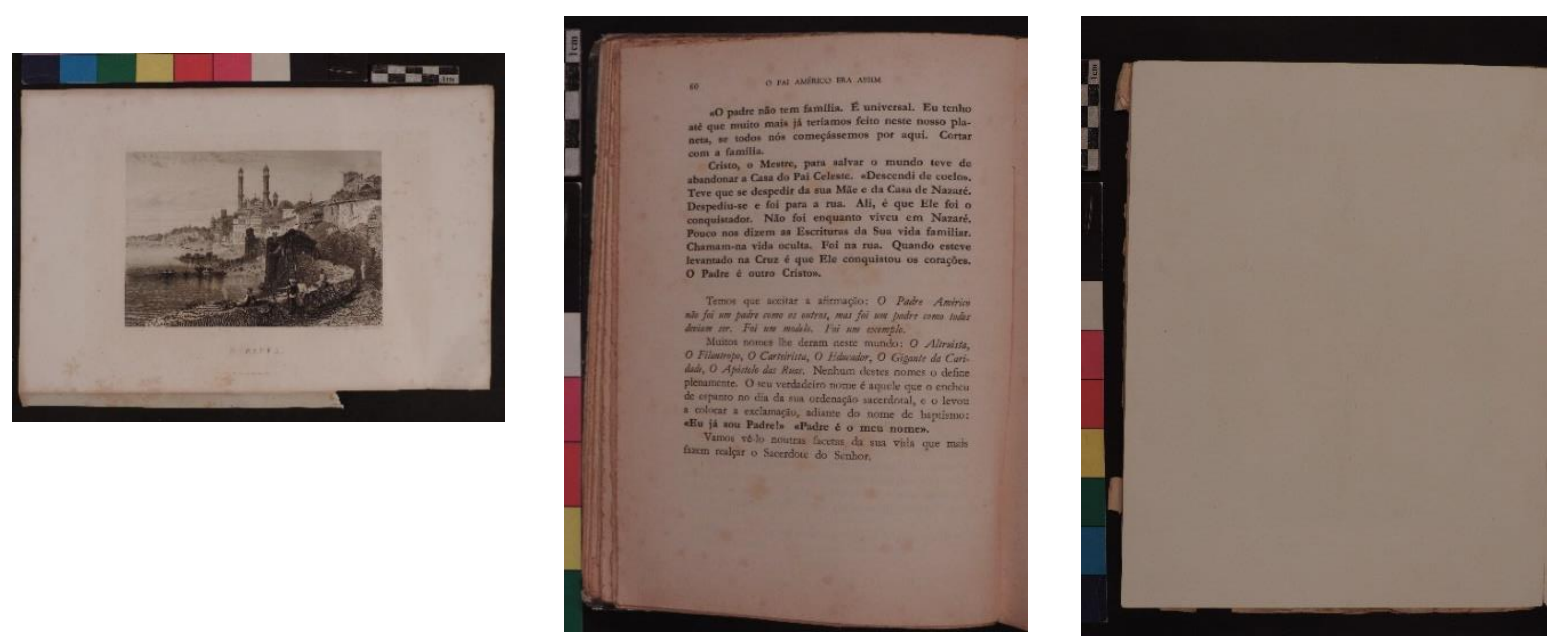

Figure 1 Photographic images of paper samples $\mathrm{P}, \mathrm{NB}, \mathrm{OB}$ obtained under standard light; Legend: a) $\mathrm{P}$, b) $\mathrm{NB}$ and c) $\mathrm{OB}$

\section{Results and Discussion}

Table 1. A descriptive summary of each sample

\begin{tabular}{l|llll} 
Samples & Texture & Color & Presence offoxing \\
\hline$P$ & Smooth & $\begin{array}{l}\text { White/without } \\
\text { gloss }\end{array}$ & $\begin{array}{l}\text { Irregular spots and high } \\
\text { concentration on its entire } \\
\text { structure, particularly the } \\
\text { verso part }\end{array}$ \\
$N B$ & $\begin{array}{l}\text { Slight } \\
\text { texture surface } \\
\text { Very smooth like } \\
\text { coucheé }\end{array}$ & Off white & $\begin{array}{l}\text { Uniform spots on the entire } \\
\text { surface } \\
\text { not visible to the naked eye } \\
\text { but visible under UV } \\
\text { radiation }\end{array}$
\end{tabular}




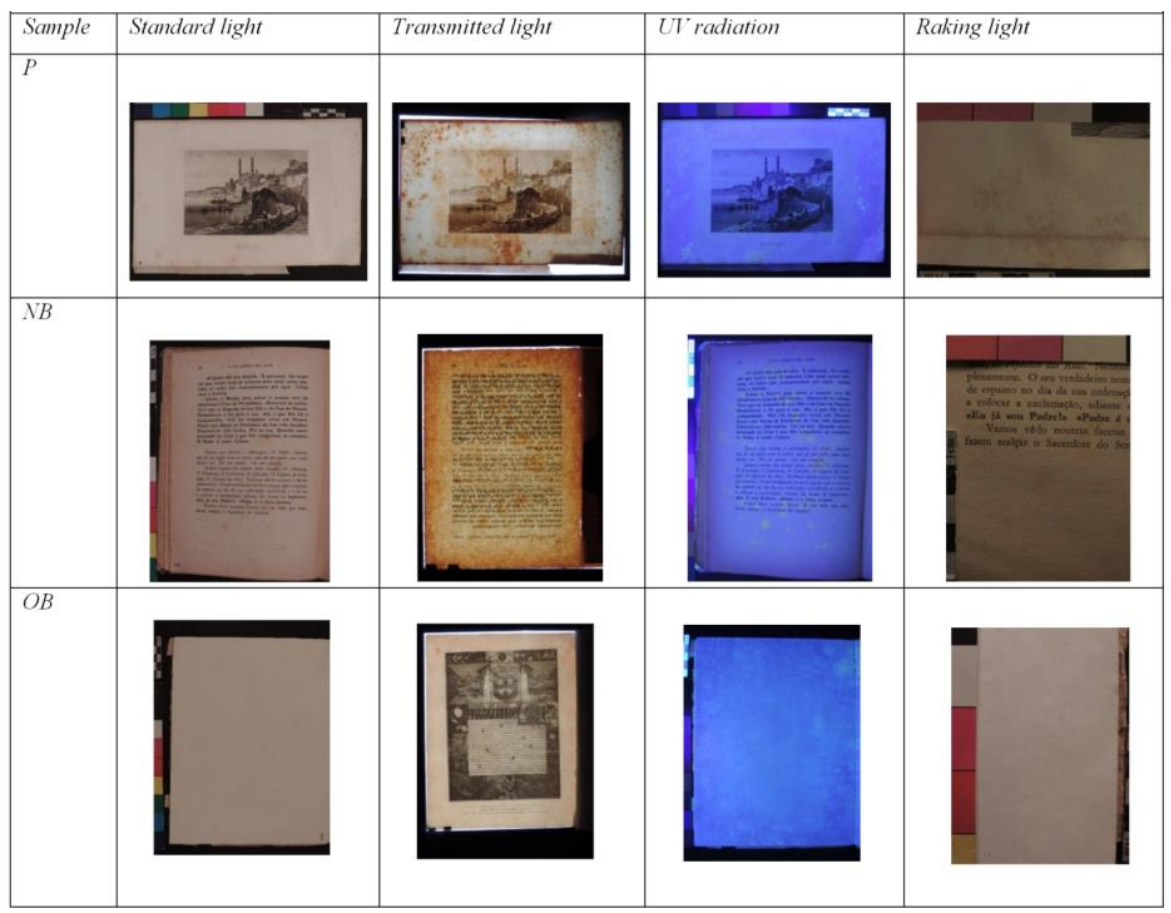

Figure 2. Photographic Images of the Paper Samples under different illuminations

For a more detailed view, the paper samples were observed by optical microscopy with different magnifications (Table 3) which allowed a better morphological discription of the foxing stains. In the table 3 is presented also the paper sample $O B$ only for the unfoxed areas because foxing stains in the page that is analyzed are not visible to the naked eye but visible under UV radiation. 


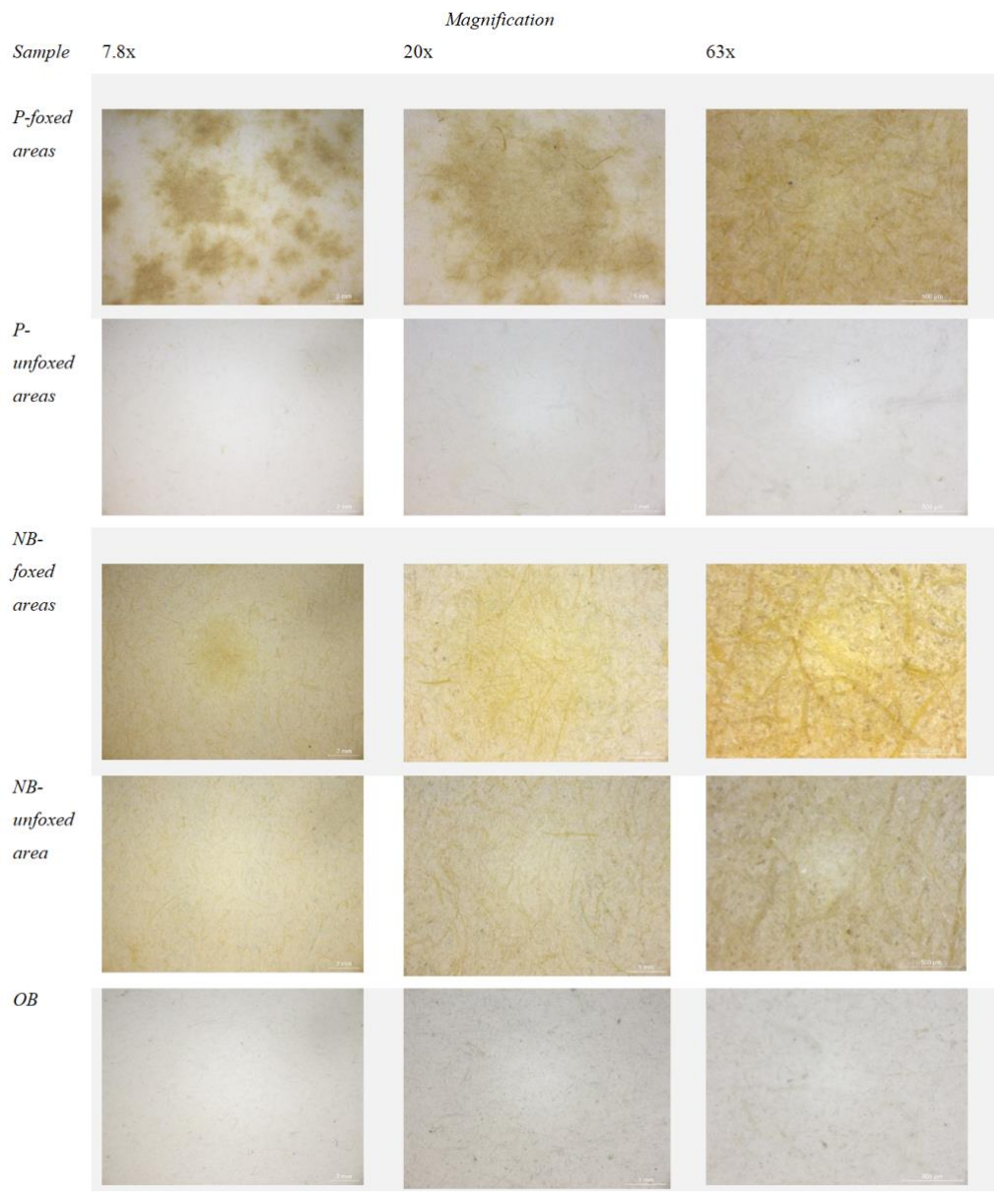

Figure 3. Optical microscopy observation

The scanning electron microscopy (SEM) analysis allowed to observe the surfaces of paper samples in the foxed and unfoxed areas at high resolution in the backscattered electron imaging mode and also to determine the main elemental components by EDS analysis. 


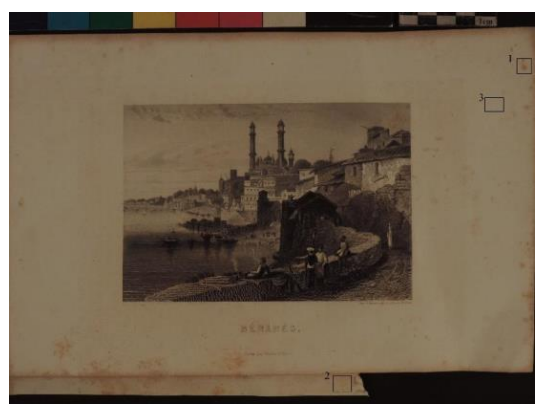

Figure 4. Areas of analysis selected for the SEM-EDS study; Legend: 1- area containing darker stains, 2- area from the whitish stains, 3-unfoxed area

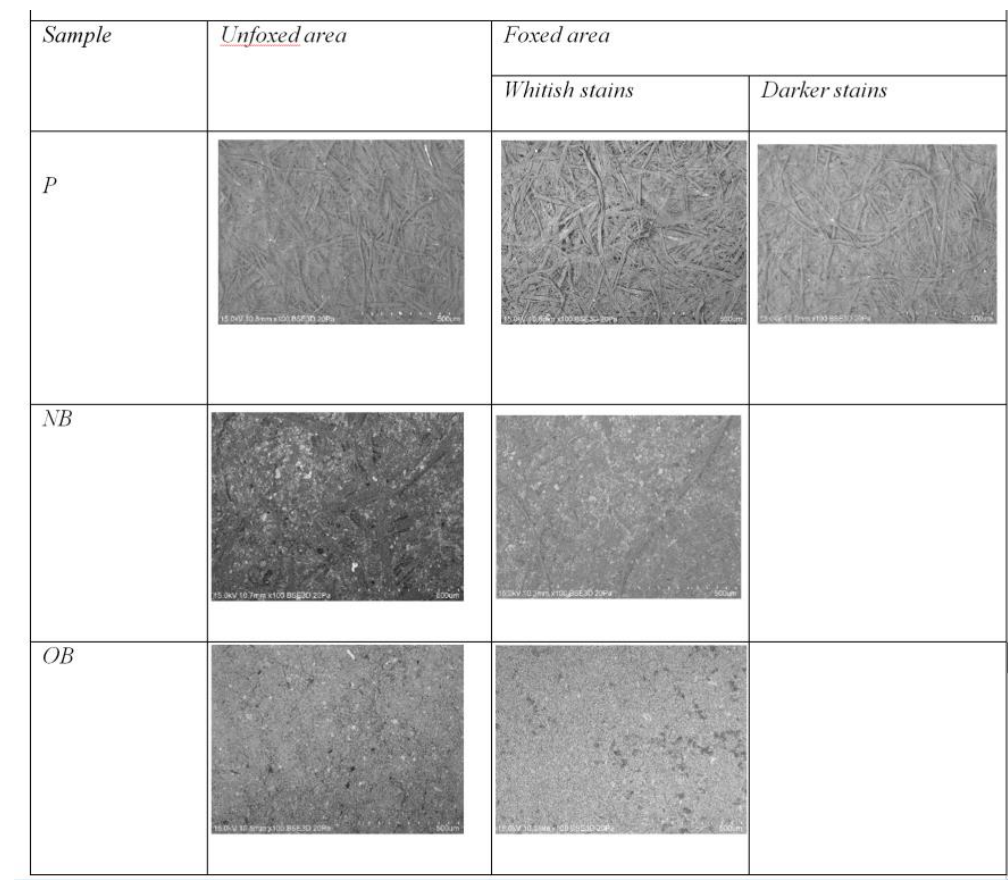

Figure 5. Scanning electron microscopy micrographs of foxed and unfoxed areas in paper samples $\mathrm{P}, \mathrm{NB}$ and $\mathrm{OB}$

EDS analysis was used to obtain information on the elemental composition of paper samples. Elemental mapping (Fig.3) of unfoxed area in paper sample $P$ revealed the presence of silicon $(\mathrm{Si})$, aluminum $(\mathrm{Al})$ and calcium $(\mathrm{Ca})$, the paper is homogenous and elements are not spread. Particles rich in calcium indicate the presence of $\mathrm{CaCO}_{3}$ that can be produced when lime easily reacts with atmospheric carbon dioxide Lime was used during the production of paper for the beating process of rag fibers The presence of aluminum $(\mathrm{Al})$ and silicon $(\mathrm{Si})$ was detected in this sample, suggesting the use of aluminum silicate as filler during the production of paper or more probably resulting from some type of contamination, like dust 


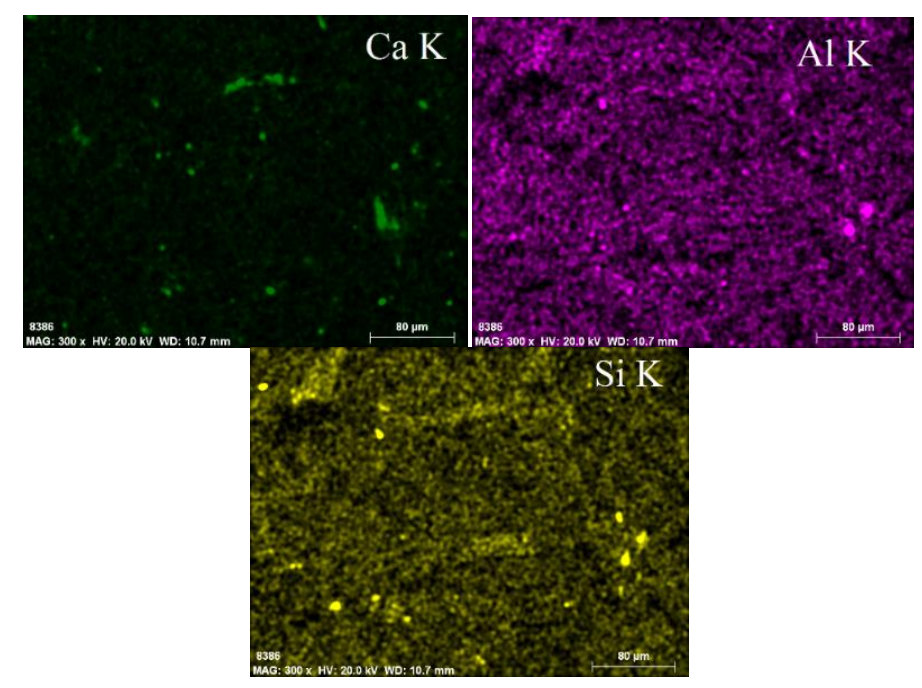

Figure 6. Elemental mapping of sample P (unfoxed area)

EDS mapping of unfoxed and foxed area (fig. 4) in paper sample $N B$ revealed the presence of silicon $(\mathrm{Si})$, aluminum $(\mathrm{Al})$ and potassium $(\mathrm{K})$, elemental composition inferred that paper contain aluminum silicate as filler with potassium that can be from muscovite.

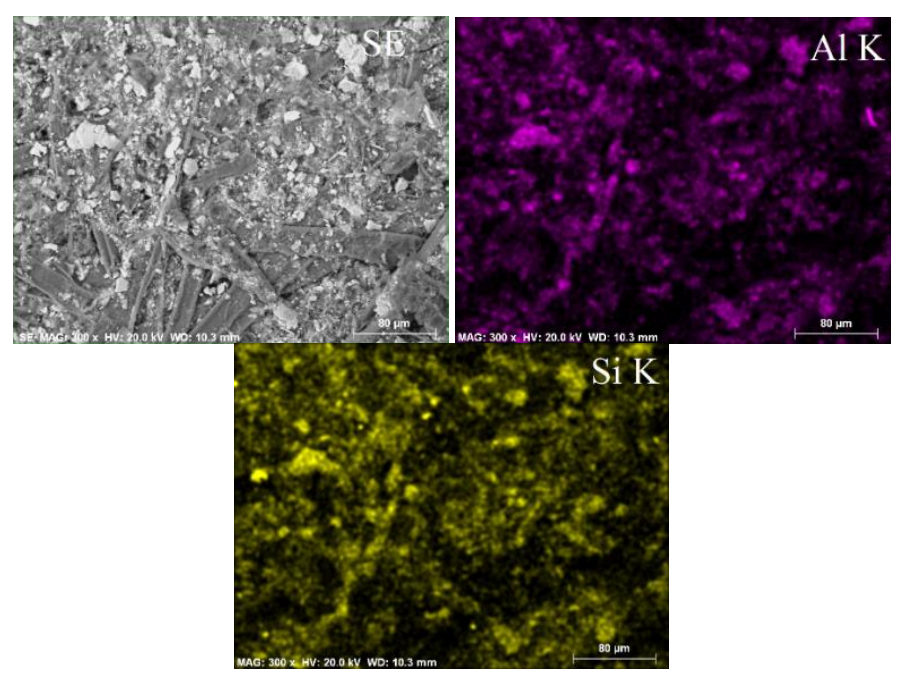

Figure 7. EDS elemental mapping for the foxed area in paper sample NB 
ATR-FT-IR analysis is used to identify organic and inorganic constituent of the paper as organic coating and others materials of interest that are present on unfoxed and foxed areas of the paper samples.

In figure 5 are presented all the AT-FT-IR spectra of samples $P, N B, O B$. The spectra are representative of several analyses done in the non-foxed and foxed areas.
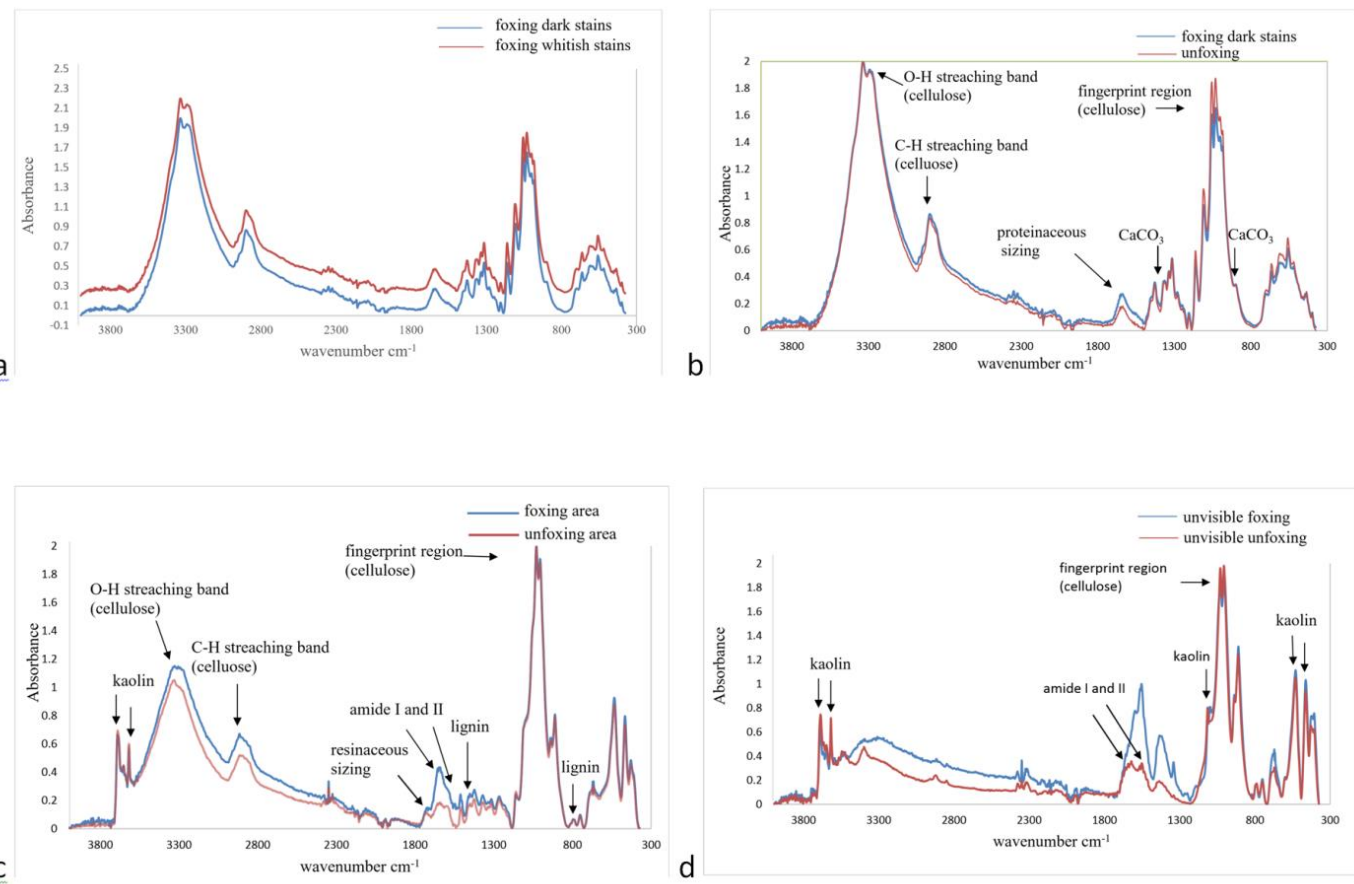

Figure 8. Attenuated total reflection Fourier transform infrared spectra of foxed dark stains (blue line) and foxed whitish stains (red line) of paper sample a)P, b) unfoxed (red line) and foxed darker areas (blue line) of paper sample $\mathrm{P}$ and unfoxed (red line) and foxed areas (blue line) of paper sample c) NB, d) OB

Micro XRD analysis on the paper samples $P, N B$ and $O B$ was carried out in order to evaluate cristalline fillers in the sample. 

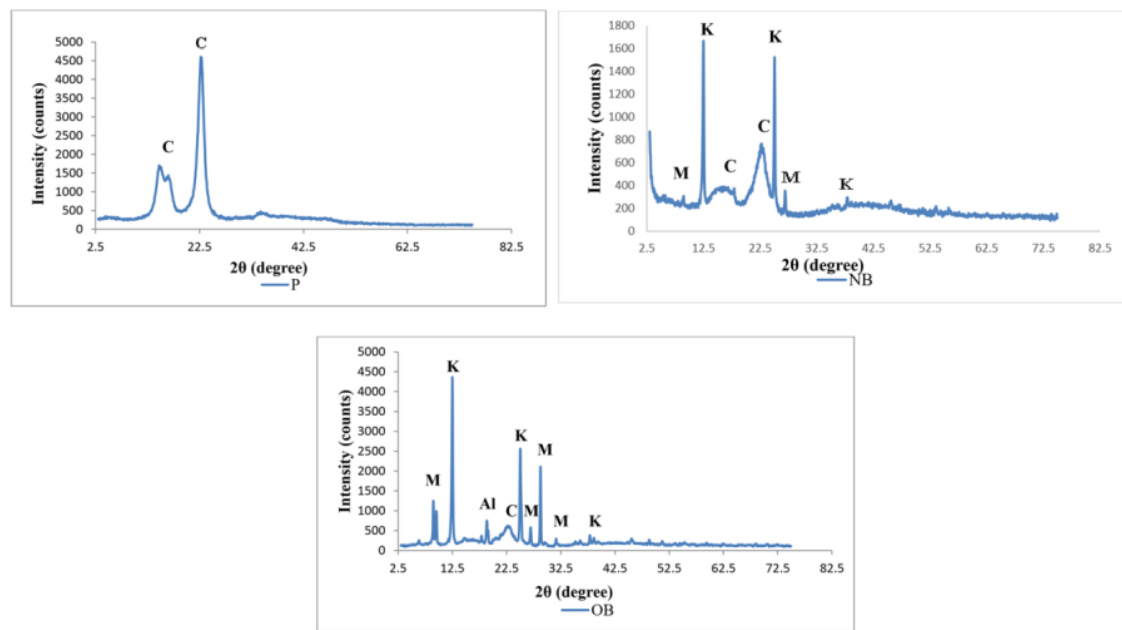

Figure 9. Micro-XRD diffractogram of paper sample P,NB,OB; C-cellulose, M-muscovite, Kkaolinite, Al- Aluminium Magnesium Hydroxide Silicate

$\mathrm{Py}-\mathrm{GC} / \mathrm{MS}$ is an analytical technique widely used for characterization of paper and in this work it was used to study the different papers and investigate possible differences in the composition of the foxing stains and unfoxed areas.

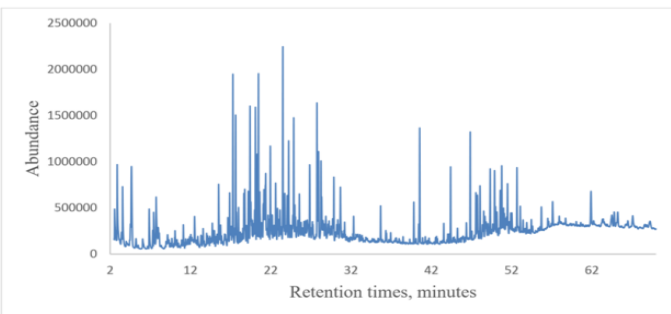

a)

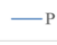

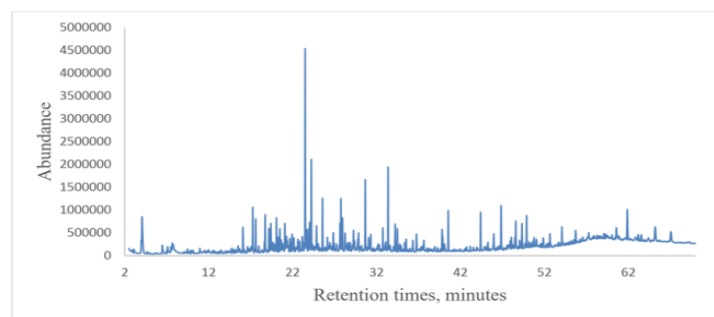

b)

$-\mathrm{NB}$

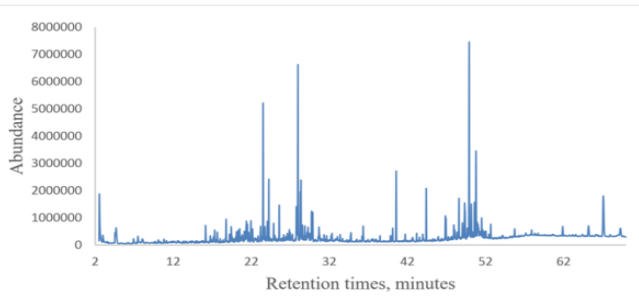

c)

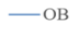

Figure 10. Py-GC/MS pyrogram of sample a) P, b) NB, c) OB 


\section{Conclusion}

The study was done for three paper samples, labeled NB (new book) dating from 1931, OB (old book) dating from 1951 and $\mathrm{P}$ (print). The materials used in production of paper and foxing stains, a type of degradation process, were evaluated for this group of investigated samples. Detailed investigation of the composition of each paper sample was done based on a non-invasive approach described in the section of materials and methods.

The first part focused on the visual and photographic description of paper samples, with the objective to characterize as much as possible.

EDS analyses indicate the presence of different elements such as calcium, aluminum, silicon, potassium, iron, magnesium and phosphorus among others.

$\mu$-XRD analysis of paper sample P showed the presence of cellulose. The presence of others minerals, kaolin and muscovite were observed in paper samples NB and OB, muscovite was in larger quantities in paper sample $\mathrm{OB}$. In the paper sample OB, aluminium magnesium hydroxide silicate was also present. Paper samples were analyzed also with Py-GC/MS, this technique is widely used for characterization of paper. Concerning paper sample $\mathrm{P}$, the identified compounds derived mainly from cellulose but also other compounds were present as lignin and hydrocarbons. In the paper sample $\mathrm{NB}$ and $\mathrm{OB}$ were identified compounds from carbohydrates, lignin, hydrocarbons, protein and resin. The combination of several non-destructive techniques allowed the characterization of paper composition and the evaluation of morphological aspects.

\section{References}

1. Adams, J., 2011. "Analysis of printing and writing papers by using direct analysis." International Journal of Mass Spectrometry 301 109-126.

2. Abdel-Maksoud, G., 2011. "Analytical techniques used for the evaluation of a 19th century quranic manuscript conditions." Measurement 1606-1617.

3. Beazley, K. 1991. "Mineral fillers in paper." Paper Conservator: Journal of the Institute of Paper Conservation 15(1) 17-27.

4. Buzio, R., Calvini, P., Ferroni, A., Valbusa, U. 2004. "Surface analysis of paper documents damaged by foxing." Applied Physics A, Materials Science \& Processing $79383-387$.

5. Boruvka, N. 2008. "The Development of Foxing Stains on Samples of Book Paper after Accelerated Ageing." Canadian Association for Conservation 33 38-45.

6. Bicchieri, M., Ronconi, S., Romanob, F.P., Pappalardoc, L, Corsid, M.,

Cristoforettid, G., Legnaiolid, S., Palleschid, V., Salvettid, A., Tognonid E. 2002. "Study of foxing stains on paper by chemicalmethods, infrared spectroscopy, micro$\mathrm{X}$-ray fluorescence spectrometry and laser induced breakdown spectroscopy." Spectrochimica Acta Part B 57 1235-1249. 